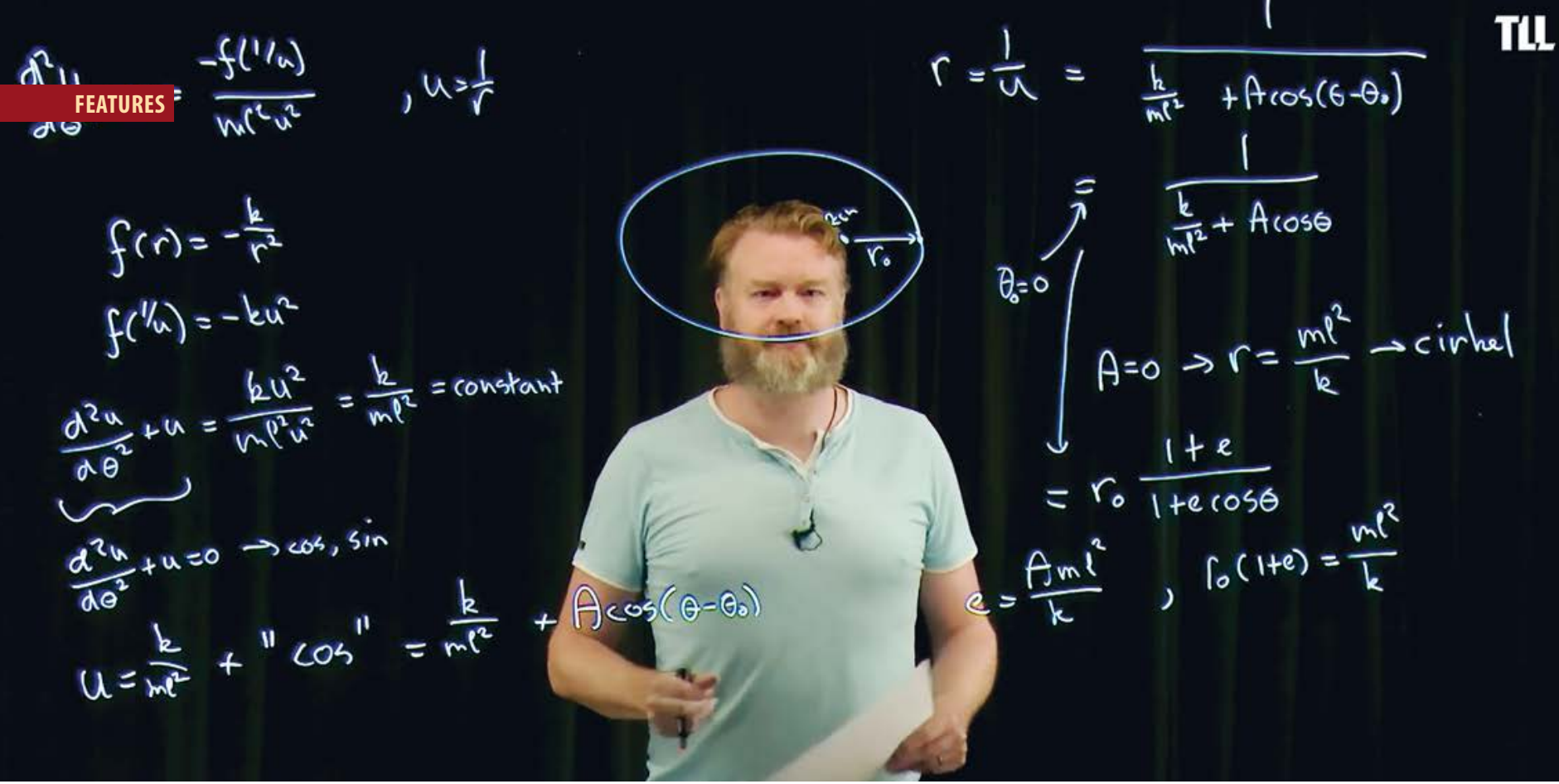

\title{
ACADEMIC TEACHING DURING A PANDEMIC: CLASSICAL MECHANICS AND SPECIAL RELATIVITY AT A DISTANCE
}

I Dries van Oosten - Utrecht University, the Netherlands - DOI: https://doi.org/10.1051/epn/2021203

\section{In the spring of 2020, the schools and universities in the Netherlands were closed for the first time. Urgently and unexpectedly, teaching had to be organised differently. At the time, our students at Utrecht University were well in their third quarter already.}

\ Still from one of the clips showing Dries van 0osten, author of this article

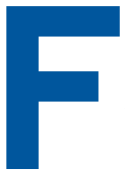

or that reason the time left to properly prepare for online teaching was minimal. Personally, I knew that a few months later in September it would be my turn to teach my students online and I started to think about a teaching model that could work. Here, I report how I planned and implemented that model.

I teach a first-year course on Mechanics and Relativity Theory. A larger number of students than usual were expected, because many of them could not take the final national school exams, since these were cancelled due to corona measures. Moreover, it was already clear that after the summer, the restrictive measures would come back again. It was crucial to choose an educational model that could withstand regular staff downtime and technical difficulties; that makes most effectively use of the time on campus that we were granted; that will teach students to work independently as quickly as possible; and that allows students to motivate each other in small groups. It was essential that the structure and working method would be clear from the start, so that I could immediately offer students structure and regularity. The teaching structure I chose comprised:

- Only once per week on-campus tutorial in a fixed workgroup of four students (three hours per week + three hours per week for other courses).

- One permanent assistant per mentor group of twelve to sixteen students (i.e., three to four workgroups) that together form a team.

- Online tutorials with the same workgroups in the mentor group.

- Core of the lectures to be pre-recorded in short knowledge clips.

- Watching the knowledge clips is scheduled and mandatory, during this time assistance is available online. 
What is still lacking in this structure is the possibility of giving students some say in the type of examples being discussed through plenary questions. For this I introduced the "Friday question". Each mentor group could submit a question on Thursday before 17:00, on the basis of which I gave a lecture on Friday morning during a live stream. These questions were often about details in the material, but also about how you see the material in current affairs.

\section{Knowledge clips}

For recording knowledge clips I used the Lightboard, a facility for which the Freudenthal Institute of Utrecht University has set up a studio, complete with technical support [1]. A Lightboard is a light-framed glass plate that is written on with fluorescent markers (see introduction figure). By using the Lightboard, I structured the lecture in suitable blocks of about ten minutes. Wiping out in between is not possible on a Lightboard, so care had to be taken that one board would be enough to work everything out. In total I recorded 64 clips, in four sessions of fourteen hours in total. I left minor mistakes and redid only two or three clips. The idea was that I would also make mistakes during a live lecture and perfectionism would simply have taken too much time. A risk in offering the material in the form of knowledge $\bullet \bullet \bullet$

\section{STUDENT INGMAR}

It was amazing how smoothly and naturally online education runs. Especially the lectures can easily be followed online. Clips have the advantage that you can choose when and at what speed you get the material explained. In addition, they remain available, making it easier to refresh your knowledge. It is a pity that the lectures have now mainly become an individual affair. When in a lecture hall, you would exchange meaningful glances or comments, people usually turn off the microphone and webcam online to focus on the material. Tutorials are a bit more difficult online. Talking to each other is generally more difficult when you don't see each other; so is asking questions, consulting or explaining each other. Anyone who has ever tried to read a math equation knows what I'm talking about. In addition, in my experience, online you tend to wait longer to ask help from an assistant. Since I am a fresh first year student in 2020, I know no better than home lectures in corona time. But still: if you walk through those empty corridors of the university buildings on campus twice a week, you realise how much you actually miss. - Ingmar Degroote, student of a double bachelor's degree in physics and mathematics.

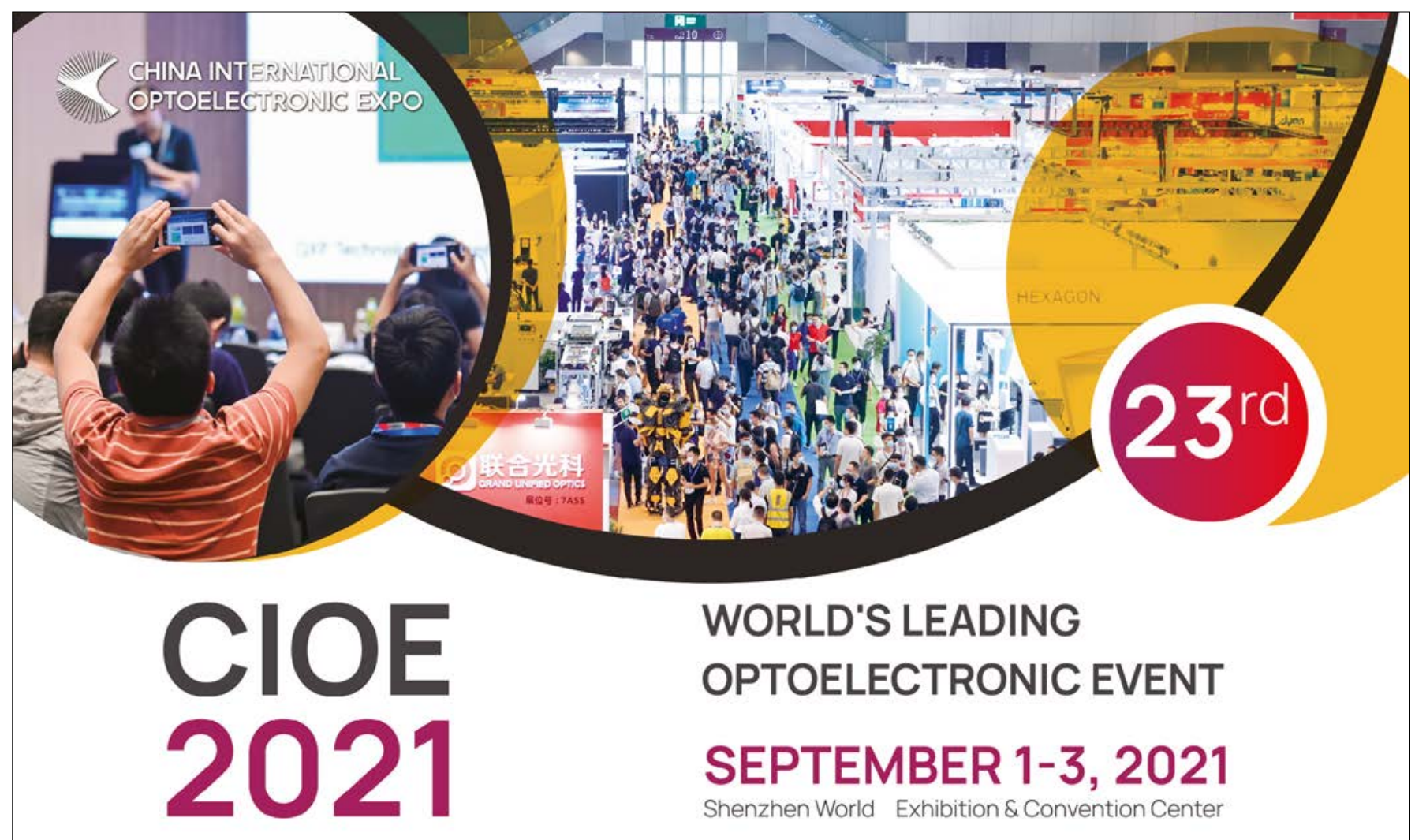




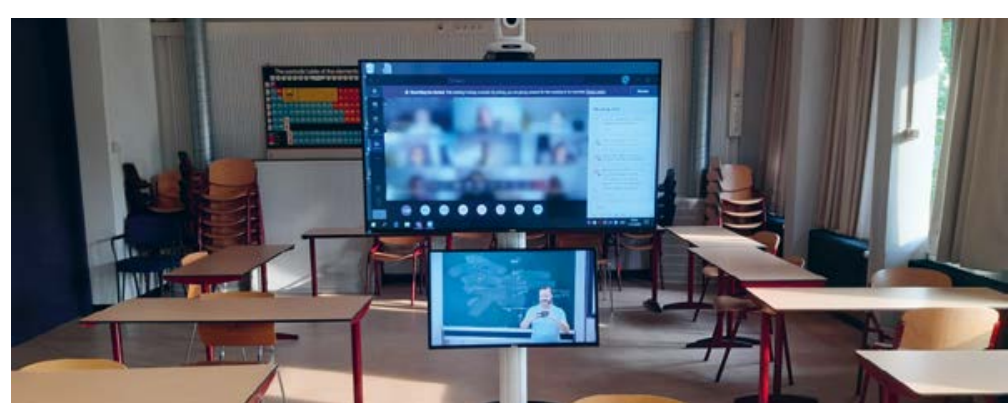

$\triangle$ FIG. 1:

Picture of the setting in which the online course was given.

- clips is that students experience viewing the clips as non-binding. After all, in online lectures social control is lacking and for students it is tempting to think that they can always watch those clips later. Certainly there would be students who did not watch the clips or only watched them when they could not solve the tutorial exercises.

In order to have some social control, I explicitly put the viewing of the clips in the schedule. As an extra incentive, direct online help with the clips was only available during these scheduled times. In addition, watching the clips was a workgroup activity. So the students were present in a meeting with their workgroup while watching in MS Teams. The students also made interim assignments (together) to promote further discussion about the clips. If workgroups were not online, I could see that in MS Teams and I could address students about it.

\section{STUDENT LISA}

I appreciated how the Mechanics and Relativity course in MS Teams was organised. For each workgroup of four students a channel was created. We usually viewed Dries' knowledge clips together and helped each other during the online seminar. This small-scale set-up made me dare to ask my questions and to enter into discussions with my fellow students. In another channel we could ask for the help of our assistants. This worked very well. It was annoying that it is difficult to share workedout solutions in MS Teams. In the program it is possible to use a whiteboard, but writing with a mouse is difficult. I also found the tutorials (twice three hours) a bit on the long side. I am very satisfied with the knowledge clips. There was not one long recording per week, but always eight shorter clips well connected to each other with the iconic phrase: "But what if ...? We will see that in the next video."The Friday questions often went deeper. As a result, the answers were not always part of the material we had to master for the exams. However, they did give the opportunity to look at a subject in a cross-curricular way, which was very valuable. It certainly helped that Dries was able to turn it into a well-coherent story every time. All in all, I think the approach is successful, although of course I cannot compare: unfortunately I do not know what"normal" is like. - Lisa van Eij, student of the double bachelor's degree in Physics and Chemistry.

\section{Tutorials}

In the tutorials the students must work with the material and learn to solve problems independently. Students sat on campus in groups of four, of course keeping a proper distance within the group. Four of these groups together with one larger mentor group fit in a (large) room. An assistant was linked to the mentor group, which allowed them to bond with the students. Because the students worked together intensively during the tutorial on campus and quickly realised what they could achieve together, they could also work together effectively during the online tutorial. The configuration also made up for funny scenes. If, for whatever reason, a student could not come to the tutorial session, a fellow student simply placed a laptop on the empty space of the student, so that they could participate via MS Teams.

\section{The Friday-question livestream}

Every Thursday evening at 17:00 PM, the preparation for Friday morning's lecture started. It turned out to be quite a challenge to put together a coherent 45-minute lecture on the basis of about twenty individual questions. However, I made a solemn promise to the students that every question would be answered. If a question really didn't fit the rest of the story, I answered it in the chat on MS Teams, but in general a lot of questions went the same way. What was discussed on Friday was not exam material, so everyone who attended was there purely out of interest. The questions went quite deeply, and I often had to bring in general relativity, quantum mechanics or fluid dynamics on Friday. For the live stream, owe use the system shown in Figure 1. A camera that can be aimed at various boards using foot switches and a monitor large enough to read the chat and see some of the students.

\section{Back to the old normal?}

We all assume that one day we will be able to offer education without restrictions again. Then the question will arise: how would I organise my education if it is allowed to be "normal" again? Do I still want to go back to the situation of the past? The students are very enthusiastic about the clips; they can pause a video, but they cannot pause me. The added advantage is that I have more time during the course to speak to students individually. In any case, the students find me much more accessible this year than in previous years. My office was always open to students, but especially first year students normally do not easily come in. Since the online course they don't know any better: post a question on MS Teams and the teacher will respond. Working in small groups also generally worked very well; the only question is whether I will get so many student assistants to help organise my course without this emergency. Of course, the students prefer to see each other more often on location, but perhaps offering an online component is a way to stimulate 
working in smaller groups and above all to make it easier to approach the teacher.

\section{Acknowledgments}

I like to thank Fridolin van der Lecq, Robin van Damme and Arjen Vredenberg.

\section{About the author}

Dries van Oosten is associated professor at University Utrecht, the Netherlands. In 2004, he obtained his PhD at the same university. His group conducts research into Bose-Einstein condensation of light and extremely nonlinear optics.

This feature has been published in Dutch in the Journal of the Netherlands Physical Society, NTvN 87/2, 2021.

\section{References}

[1].https://science.educate-it.uu.nl/lightboard.

[2] https://lightboard.info/

\section{DIRECTOR OF EDUCATION PETER}

In the spring of 2020, physical education in universities was stopped overnight and all lectures were offered online. Before the summer it soon became clear that this situation will not change for a long time. In Utrecht, we 'sat around the table' with various teachers to further assess the implications. We discussed questions such as: How can we offer the material to the students as optimally as possible? How do we keep the students actively involved in a course? How can we provide feedback to the students as clearly as possible, but also as efficiently as possible? How we can provide students with possibly making the transition from high school to university thinking, came into a different light and forced us to come up with new answers. In this article, one of our teachers explains how he dealt with this in his course, which for the students is their first introduction to physics and astronomy. - Peter van der Straten, Education Director Physics and Astronomy.

\section{COMPANY DIRECTORY}

\section{BARTINGTON INSTRUMENTS www.bartington.com \\ Bartington Instruments designs and manufactures high precision fluxgate magnetometers, Helmholtz coil systems, gradiometers, magnetic susceptibility instruments and associated data processing equipment, for the precise generation and measurement of magnetic fields around physics experiments, and for calibration of magnetometers in consumer electronics.}

\section{BLUEFORS OY}

\section{Bluefors.com}

Bluefors manufactures cryogenic measurement systems and has a strong focus in the field of quantum technology. Our reliable and easy-to-operate systems can be customized to meet the special requirements of each experiment allowing the customer to get in direct contact with the scientists and engineers who design their system.

\section{TOPTICA PHOTONICS}

\section{MCPHERSON}

\section{www.mcphersoninc.com}

McPherson designs and manufactures scanning monochromators, flat-field imaging spectrographs, and vacuum monochromators and measurement systems for reflectance, transmittance, and absorbance testing. Its spectrometers and systems are built for soft $\mathrm{x}$-ray, vacuum-ultraviolet, and UV/Vis and Infrared wavelengths. Applications range from lasers and lithography, solar, and energy to analytical life science and more.

\section{www.toptica.com}

TOPTICA Photonics, founded in 1998 near Munich (Germany), develops and manufactures high-end laser systems for scientific and industrial applications. The portfolio includes diode lasers, ultrafast fiber lasers, terahertz systems and frequency combs. OEM customers, scientists, and over a dozen Nobel laureates all acknowledge the world-class exceptional specifications ofTOPTICA's lasers, as well as their reliability and longevity.

\section{INTERMODULATION PRODUCTS AB} intermodulation-products.com We develop and sell high-speed multichannel, multifrequency lock-in amplifiers with specialized signal processing capabilities for non-linear systems. In particular we have applications for determining the tip-surface force in tapping mode AFM, and an all-in-one measurement and control instrument for quantum computing.

\section{ZURICH INSTRUMENTS} www.zhinst.com

Zurich Instruments is a technology leader developing and selling advanced test \& measurement instruments for dynamic signal analysis. These devices are used in many fields of application by hightechnology research laboratories and industrial development sites. Zurich Instruments' vision is to revolutionize instrumentation in the high-frequency and ultra-high-frequency rangebyincorporating the latest analog and digital technology into powerful measurement systems. 